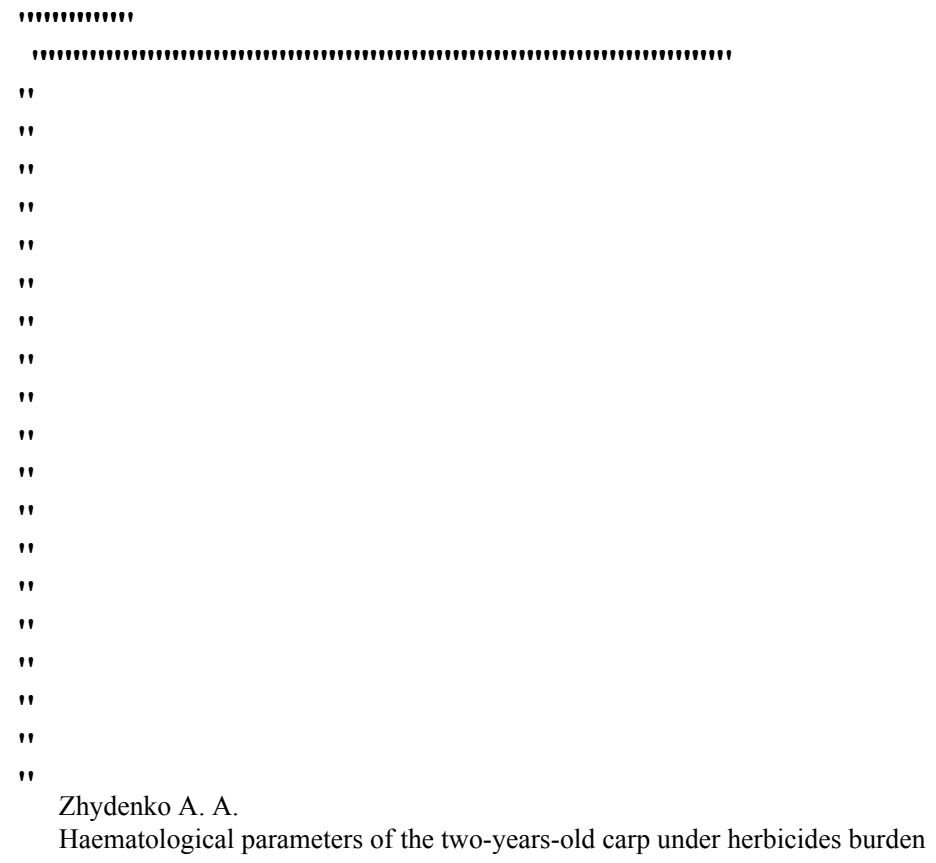

УДК 597.551.2 : 691.111.1/4 : 574.64

А. А. Жиденко

Черниговский государственный педагогический университет им. Т. Г. Шевченко

\title{
ГЕМАТОЛОГИЧЕСКИЕ ПОКАЗАТЕЛИ ДВУХЛЕТОК КАРПА В УСЛОВИЯХ ГЕРБИЦИДНОЙ НАГРУЗКИ
}

Проаналізовано вплив гербіцидів різного хімічного складу в кількості 2 ГДК (гранично допустимі концентрації) на зміни головних гематологічних показників і формування адаптації у дволіток коропа. Терміновий етап адаптаційних реакцій формується швидше і більше виражений у риб під дією зенкору; поступовий розвиток довготривалої адаптації спостерігасться за умов дії раундапу. Наслідком впливу похідних 2,4-Д с зниження наступних показників крові: вмісту гемоглобіну, кольорового показника, ВГЕ (вмісту гемоглобіну в еритроциті), ШОЕ (швидкості осідання еритроцитів), що свідчить про уповільнення формування адаптаційних реакцій у дволіток коропа.

Influence of different chemical herbicides in a concentration of 2 MAC (maximum allowable concentration) on changes of the basic haematological parameters and formation of adaptive reactions of two-years-old carp is presented. Mostly rapid and pronounced urgent stage of the adaptive response is formed under the influence of Zencor. The gradual development of the long-term adaptation was launched by Roundup. 2, 4-D reduced the following blood parameters: the haemoglobin level, colour index, erythrocytes' haemoglobin content, erythrocyte sedimentation rate (ESR). That is the evidence of non-formation of adaptation.

\section{Введение}

Ежегодно в производство внедряются десятки новых гербицидов для увеличения урожайности сельхозкультур и борьбы с сорной растительностью. Их применение приводит к загрязнению водоемов, созданию стрессовой ситуации для гидробионтов и, в первую очередь, рыб. Возможность выживания и создания потомства зависит от адаптационных реакций, которые возникают в ответ на действие стресс-

(c) А. А. Жиденко, 2007

Вісник Дніпропетровського університету. Біологія, екологія.

Vìsnik Dnìpropetrovs'kogo unìversitetu. Serîa Bìologiâ, ekologìa

Visnyk of Dnipropetrovsk University. Biology, ecology. Vìsn. Dnìpropetr. Unìv. Ser. Bìol. Ekol. 2007. 15(1).

ISSN 2310-0842 print ISSN 2312-301X online www.ecology.dp.ua 
фактора. При всем разнообразии индивидуальной фенотипической адаптации в ее развитии прослеживаются два этапа, а именно: начальный этап срочной, но несовершенной адаптации и последующий этап - совершенной долговременной адаптации [11]. Срочный этап адаптационной реакции возникает непосредственно после начала действия раздражителя и, следовательно, может реализоваться лишь на основе готовых, ранее сформировавшихся физиологических механизмов, что влияет на изменения гематологических показателей у рыб.

Именно кровь, являясь внутренней средой организма, отражает биохимические процессы, протекающие в клетках и межклеточном пространстве, в ответ на действие неблагоприятных факторов среды. Ю. Л. Волынкин утверждает [3], что зимой происходит медленный эритропоэз и накопление гемоглобина в организме рыб, так как выведение продуктов его разложения из организма с желчью через кишечник затрудняется. Этот процесс характерен и при псевдомонозе годовиков карпа. По мнению И. А. Парфенова [8], экспериментальная гипоксия вызывает у скорпены (Scorpaena porcus L.) достоверный рост значений гематокрита по сравнению с контролем, увеличение объема эритроцитов, объема их ядер, при сохранении их численности в крови. В работе [5] показано, что действие катионов цинка разной концентрации в воде $(0,1$, 5,0 мг/л) вызывает в крови карпа (Cyprinus carpio L.) изменения прооксидантного характера, которые связаны с увеличением интенсивности ПОЛ и уменьшением активности супероксиддисмутазы эритроцитов и плазмы. Цитируемые авторы не связывают полученные изменения показателей крови рыб ни с одним из этапов адаптации.

Хотя известно, что важнейшей чертой срочного этапа адаптации является то, что деятельность организма протекает на пределе его физиологических возможностей - при почти полной мобилизации функционального резерва. К сожалению, процесс этот не экономичен и не в полной мере обеспечивает необходимый адаптационный эффект [11]. Только долговременный этап адаптации, который возникает постепенно, развиваясь на основе многократной реализации срочной адаптации, приводит к тому, что организм приобретает новое качество, способствующее нормальному существованию в измененных условиях окружающей среды. Поэтому цель настоящей работы состояла в том, чтобы, проследив изменения гематологических показателей двухлеток карпа в ответ на действие гербицидов разного химического состава, показать особенности формирования адаптационных реакций.

\section{Материал и методы исследований}

Объектом исследования служили двухлетки карпа (Cyprinus carpio L.), выращенные в ОАО «Черниговрыбхоз» до массы 250-300 г. Влияние гербицидов 2 ПДК (предельно допустимые концентрации) проверяли путем внесения расчетных количеств 40 \% водного раствора 2,4-дихлорфеноксиуксусной кислоты аммонийной соли (2,4-ДА) или бутилового эфира (2,4-ДБЭ) $\left(0,008\right.$ мг/дм $\left.{ }^{3}\right) ; 70 \%$ порошка зенкора $\left(0,2 \mathrm{мг} /\right.$ дм $\left.^{3}\right)$ и раствора раундапа $\left(0,004\right.$ мг/дм $\left.{ }^{3}\right)$ в 200-литровые аквариумы. Рыбу помещали из расчета один экземпляр на 40 л воды, с поддержанием постоянного гидрохимического режима (величина $p H$ составляла $7,8 \pm 0,3$, содержание кислорода $5,6 \pm 0,4$ мг/л, температура воды $\left.-+6 \ldots+10^{\circ} \mathrm{C}\right)$.

На 1-е, 4-е, 7-е и 14-е сутки эксперимента у рыб брали кровь путем пункции сердца. Начальную пробу крови без первой капли использовали для определения ее свертываемости [10]. Остальную кровь стабилизировали путем добавления гепарина - 0,01\% (в 1 мг препарата 130 ЕД) [12]. Для оценки морфофункционального состояния организма определяли следующие показатели крови: количество эритроцитов (подсчет осуществляли в камере Горяева), скорость оседания эритроцитов (СОЭ),

Вісник Дніпропетровського університету. Біологія, екологія.

Vìsnik Dnìpropetrovs'kogo unìversitetu. Serîa Bìologiâ, ekologîâ Visnyk of Dnipropetrovsk University. Biology, ecology. Vìsn. Dnìpropetr. Unìv. Ser. Bìol. Ekol. 2007. 15(1).

ISSN 2310-0842 print ISSN 2312-301X online www.ecology.dp.ua 
концентрацию гемоглобина (по Сали) с использованием гемометра [9]. Исходя из полученных данных, рассчитывали содержание гемоглобина в одном эритроците (СГЭ), цветной показатель крови [9]. Кроме того, определяли вязкость с использованием вискозиметра ВК-4, удельный вес крови по Шмальцу [2], резистентность эритроцитов по О. Н. Давыдову и содержание белка по Лоури [4]. Статистическую обработку результатов проводили по И. А. Ойвину [7].

\section{Результаты и их обсуждение}

Установлена неоднозначность возможных путей формирования ответных реакций организма в течение 14 суток на действие каждого из гербицидов, о чем свидетельствует различная динамика гематологических показателей двухлеток карпа (рис. 1-7).

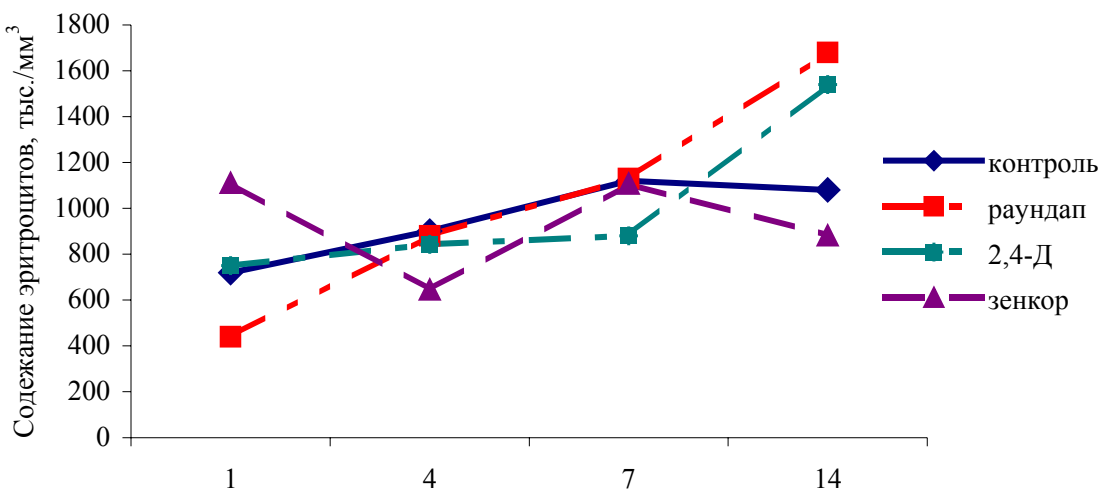

Длительность нагрузки, суток

Рис. 1. Динамика содержания эритроцитов в крови двухлеток карпа в условиях гербицидной нагрузки

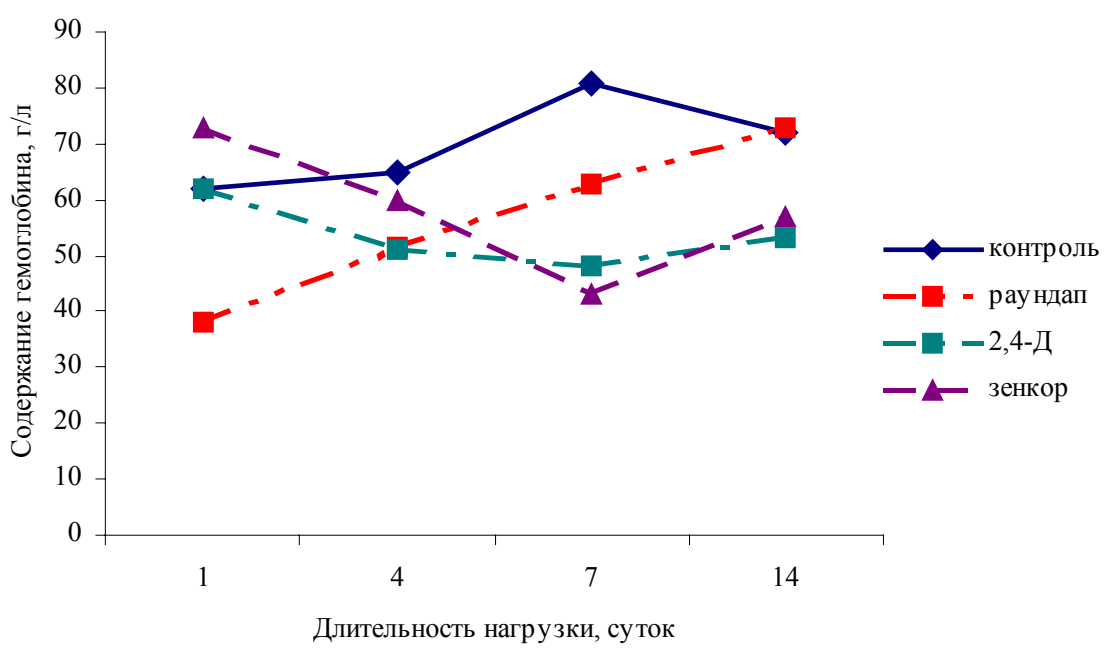

Рис. 2. Динамика содержания гемоглобина в крови двухлеток карпа в условиях гербицидной нагрузки

После первых суток пребывания карпов в токсических условиях наибольшая мобилизация физиологических ресурсов организма проявляется под действием зенкора, что выражается в максимальном увеличении содержания эритроцитов, гемоглобина, белков плазмы (рис. 1-5). Косвенным доказательством последнего является увеличение СОЭ почти в четыре раза. Известно, что скорость оседания эритроцитов зависит от физиологического состояния организма, которое влияет на уровень бел-

Вісник Дніпропетровського університету. Біологія, екологія.

Vìsnik Dnìpropetrovs'kogo unìversitetu. Seriâ Bìologîa, ekologîa Visnyk of Dnipropetrovsk University. Biology, ecology. Vìsn. Dnìpropetr. Unìv. Ser. Bìol. Ekol. 2007. 15(1).

ISSN 2310-0842 print ISSN 2312-301X online www.ecology.dp.ua 
ков-глобулинов в плазме. Повышение их содержания приводит к нейтрализации отрицательного заряда эритроцитов, путем их адсорбции. Вследствие этого эритроциты образуют конгломераты, которые, будучи более тяжелыми, быстрее оседают [4]. Менее выражена срочная адаптация под действием раундапа, поскольку содержание эритроцитов, гемоглобина уменьшается в 1,6 раза. Остальные показатели по сравнению с контролем изменяются незначительно. Под действием производных 2,4-Д величины показателей крови почти не изменяются.

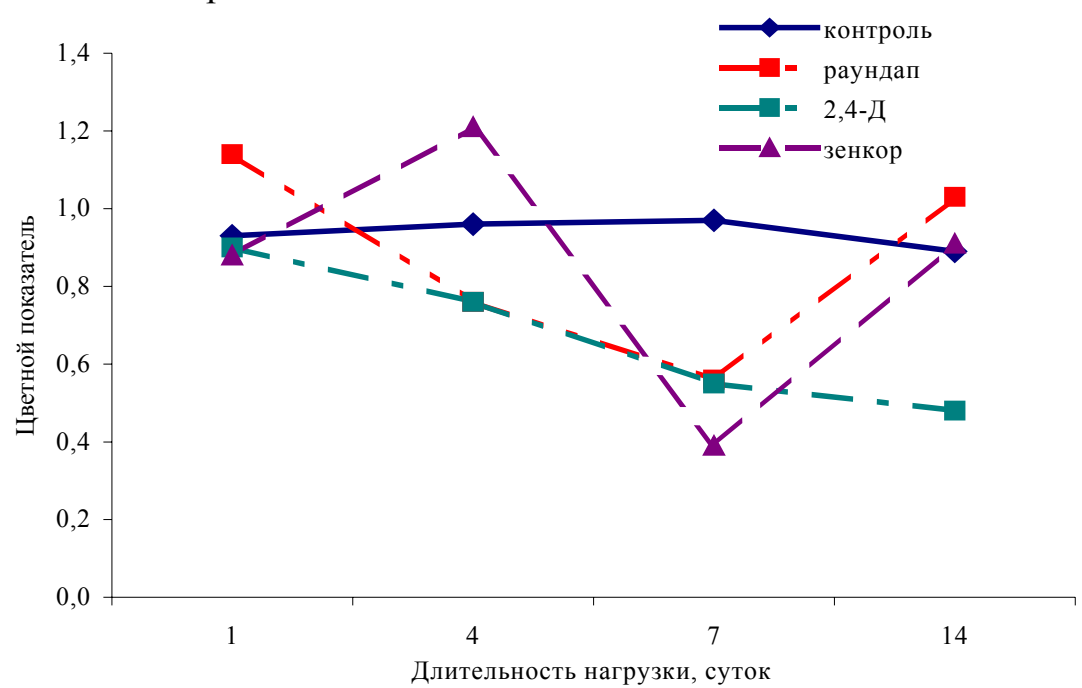

Рис. 3. Динамика цветного показателя крови двухлеток карпа в условиях гербицидной нагрузки

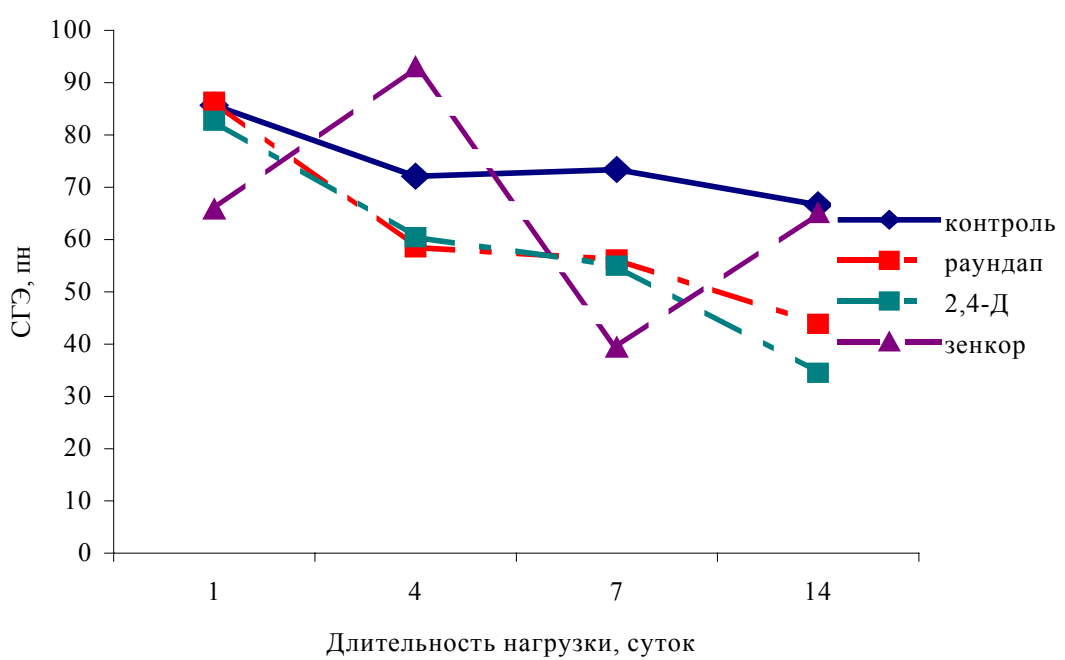

Рис. 4. Динамика СГЭ (содержания гемоглобина в эритроците) крови двухлеток карпа в условиях гербицидной нагрузки

По истечении четырех суток эксперимента количество эритроцитов изменяется неоднозначно в зависимости от природы гербицида. Под действием зенкора их количество уменьшается почти в два раза и становится меньше чем в контроле; под действием раундапа, наоборот, - незначительно отличается от контроля. Что касается действия 2,4ДА, достоверные различия в показателях не наблюдаются (см. рис. 1). Изменения уровня гемоглобина в крови двухлеток карпа под действием данных гербицидов аналогичны (см. рис. 2). Показатели скорости оседания эритроцитов резко снижаются (рис. 4).

Вісник Дніпропетровського університету. Біологія, екологія.

Vìsnik Dnìpropetrovs'kogo unìversitetu. Serìa Bìologîa, ekologîâ Visnyk of Dnipropetrovsk University. Biology, ecology. Vìsn. Dnìpropetr. Unìv. Ser. Bìol. Ekol. 2007. 15(1).

ISSN 2310-0842 print ISSN 2312-301X online www.ecology.dp.ua 
После семисуточного пребывания рыб в условиях эксперимента картина крови меняется. Под влиянием зенкора при резком снижении уровня гемоглобина в крови (см. рис. 2) происходит некоторая стабилизация содержания эритроцитов (рис. 1), но значение цветного показателя наименьшее $(0,39)$ по сравнению с контролем $(0,97)$ (рис. 3). Цветной показатель - это соотношение между количеством гемоглобина и числом эритроцитов. Он показывает степень насыщения эритроцитов гемоглобином. Кроме того, для зенкора характерным является изменение формы эритроцитов, больше становится молодых клеток, имеющих округлую форму с наименьшим соотношением диаметров, что приводит к микроцитозу (уменьшению объема эритроцитов) и ненасыщенности гемоглобином. В связи с этим показатель СГЭ наименьший - 39,36 пг (см. рис. 4).

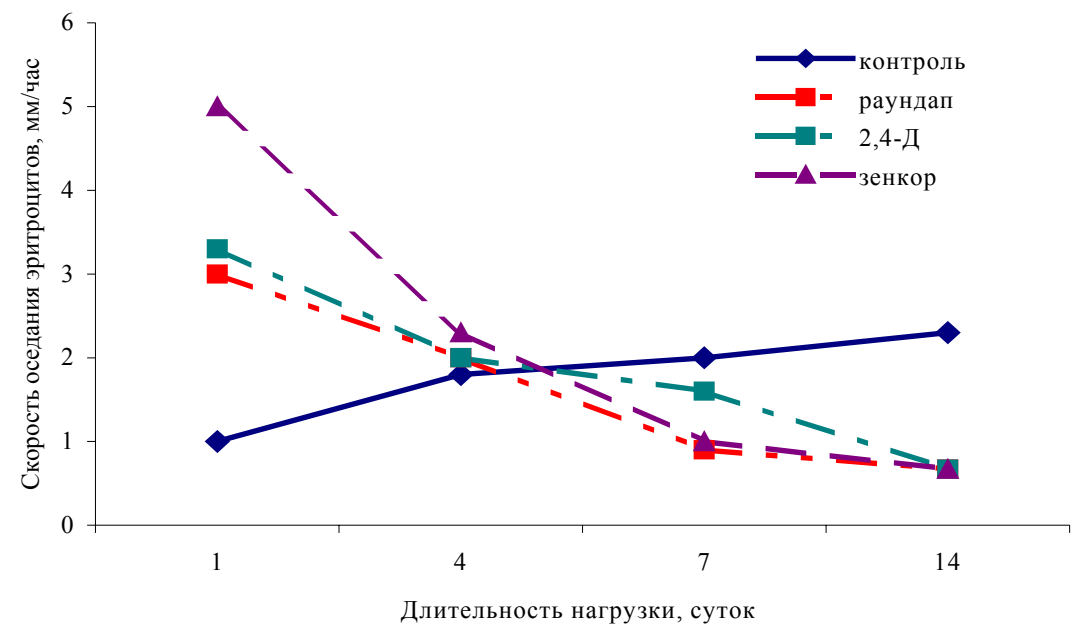

Рис. 5. Динамика СОЭ крови двухлеток карпа в условиях гербицидной нагрузки

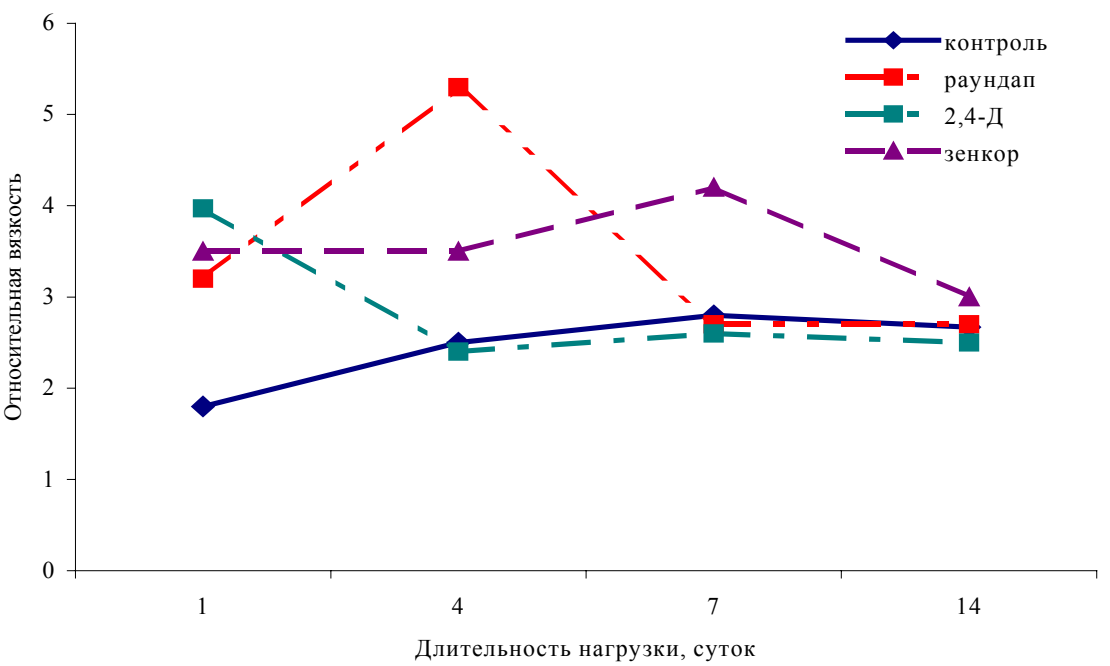

Рис. 6. Динамика относительной вязкости крови двухлеток карпа в условиях гербицидной нагрузки

Таким образом, изменения морфологии эритроцитов карпа под действием гербицидов противоположны изменениям, которые происходят с эритроцитами скорпены (набухание, обводнение) в условиях экспериментальной гипоксии [8]. Под действием раундапа этот показатель несколько выше $(56,2)$, но в 1,3 раза меньше контроля, а цветной показатель крови меньше в 1,8 раза, хотя количество эритроцитов сравня-

Вісник Дніпропетровського університету. Біологія, екологія.

Vìsnik Dnìpropetrovs'kogo unìversitetu. Serìâ Bìologîâ, ekologîa Visnyk of Dnipropetrovsk University. Biology, ecology. Vìsn. Dnìpropetr. Unìv. Ser. Bìol. Ekol. 2007. 15(1)

ISSN 2310-0842 print ISSN 2312-301X online www.ecology.dp.ua 
лось с контролем и увеличилось по сравнению с первыми сутками в 2,6 раза. Такие изменения характерны для организмов, находящихся в условиях стрессовых ситуаций при воздействии каких-либо токсических агентов [1]. Наименьшее количество эритроцитов в крови карпов, содержащихся в течение 7 суток в водной среде с повышенным содержанием производных 2,4-Д (см. рис. 1) и у них же наивысшая скорость свертываемости (см. рис. 7). Скорость оседания эритроцитов также снижается (см. рис. 5), что свидетельствует об уменьшении содержания белков в плазме и, в первую очередь, глобулинов.

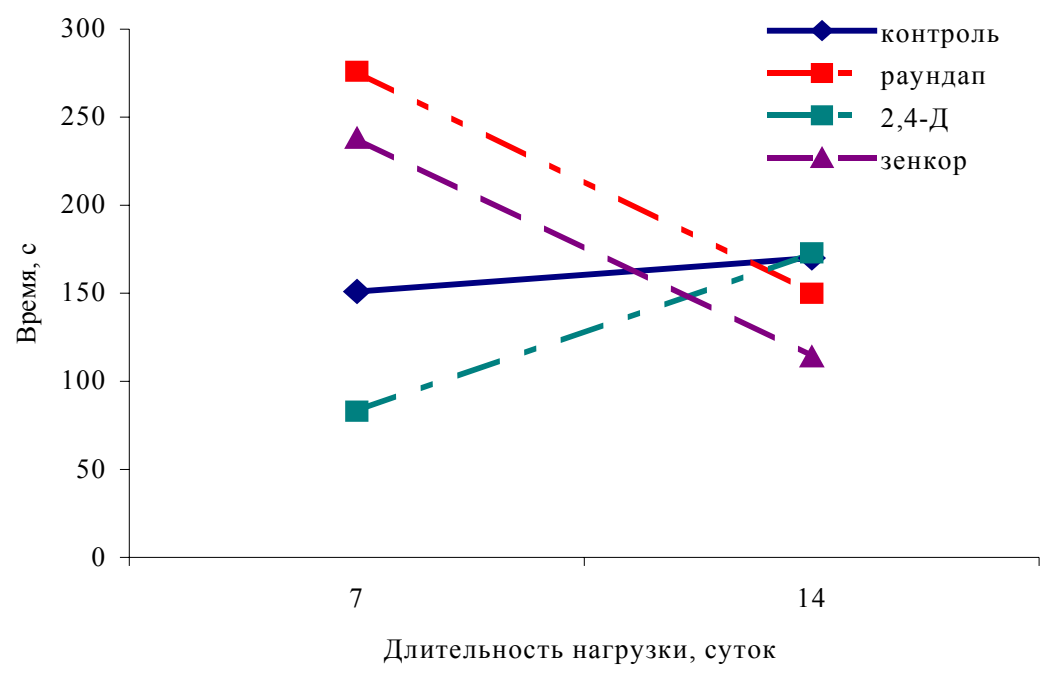

Рис. 7. Динамика свертываемости крови двухлеток карпа в условиях гербицидной нагрузки

На 14-е сутки под действием раундапа и 2,4-ДА происходит повышение концентрации эритроцитов (см. рис. 1) и уменьшение её под действием зенкора, что отражается на вязкости, уровень которой также снижается (см. рис. 6). Вязкость крови зависит от концентрации гемоглобина, количества и особенно объема эритроцитов, кроме того, от вязкости плазмы крови и количественных колебаний лейкоцитов.

Содержание гемоглобина под действием изучаемых гербицидов несколько стабилизируется, что отражается на цветном показателе крови, который по сравнению с семисуточными показаниями также приобретает стабильность, за исключением действия производных 2,4-Д. Цветной показатель под влиянием 2,4-Д меньше нормы в два раза; выравниваются также вязкость и свертываемость крови (см. рис. 6, 7). Скорость же оседания эритроцитов резко снижается и достигает наименьших величин - 0,67 (см. рис. 5), что свидетельствует о минимальном содержании белка плазмы крови. Наши данные о снижении уровня белка плазмы под действием гербицидов согласуются с результатами, описанными в многочисленных работах В. И. Лукьяненко и В. В. Метелева.

Удельный вес крови карпов, который определялся по соотношению веса крови к весу дистиллированной воды, не изменялся на протяжении 14 суток эксперимента. Влияние гербицидов не привело к развитию гидремии (понижению удельного веса) или полиплазмии (повышению содержания плазмы). Возможно, это связано с малой концентрацией гербицидов (2 ПДК) или малой чувствительностью метода. При концентрации хлорида натрия 0,1-0,3\% (гипотонический раствор) наблюдаем полный гемолиз эритроцитов (отсутствие резистентности): окраска раствора ярко-красная, лаковая, с блеском. В пробирках с более высокой концентрацией $\mathrm{NaCl}$ (переход к изотоническому) раствор мутный, наблюдается частичный гемолиз и малое разрушение эритроцитов.

Вісник Дніпропетровського університету. Біологія, екологія.

Vìsnik Dnìpropetrovs'kogo unìversitetu. Seriâ Bìologiâ, ekologîâ Visnyk of Dnipropetrovsk University. Biology, ecology. Vìsn. Dnìpropetr. Unìv. Ser. Bìol. Ekol. 2007. 15(1).

ISSN 2310-0842 print ISSN 2312-301X online www.ecology.dp.ua 


\section{Выводы}

Формирование адаптационной реакции у двухлеток карпа в ответ на действие различных гербицидов неоднозначно. Суточное действие зенкора приводит к возникновению срочной адаптации, которая выражается в увеличении количества эритроцитов, гемоглобина, СОЭ, вязкости крови. Ответная реакция организма на действие раундапа (4-е сутки) выражается в повышении содержания эритроцитов и гемоглобина в крови карпа. Показатели крови в условиях действия производного 2,4-Д после первых суток эксперимента близки к показателям контроля. Критическим этапом, когда действие срочной адаптации становится невозможным (организм исчерпал свои физиологические возможности и резервы), а формирование системного структурного следа, то есть долговременной адаптации, еще не завершено, являются 7-е сутки. Для них характерны наиболее низкие гематологические показатели, которые неблагоприятны для функционирования организма рыб.

О формировании долговременной адаптации в организме двухлеток карпа (более стабильные гематологические показатели) на 14-е сутки можно говорить только в случае действия раундапа. Изменения показателей крови, наблюдаемые под влиянием зенкора, свидетельствуют о незавершенности процесса формирования долговременной адаптации. Наихудшие гематологические показатели (за исключением количества эритроцитов) зафиксированы под действием производных 2,4-Д, вероятно потому, что ярко выраженной срочной реакции и мобилизации внутренних ресурсов в первые сутки не наблюдалось. Постепенное накопление этого гербицида [6] приводит к нарушениям функций крови.

\section{Библиографические ссылки}

1. Бугаев Л. А. Мониторинг гематологических показателей азовского судака / Л. А. Бугаев, О.А. Рудницкая, А. С. Засядько // Актуальные проблемы экологической физиологии, биохимии и генетики животных. - Саранск: Изд-во Мордов. ун-та, 2005. - С. 36-38.

2. Васильев А. В. Гематология сельскохозяйственных животных. - М.: СельхозиздательстBо, 1948. -439 c.

3. Волынкин Ю. Л. Взаимосвязь морфофизиологических и гематологических показателей сеголетков карпа в период зимовки // Современные проблемы популяционной экологии. Матер. IX Междунар. научно-практ. конф. - Белгород: Политера, 2006. - С. 37-38.

4. Давыдов О. Н. Патология крови рыб / О. Н. Давыдов, Ю. Д. Темниханов, Л. Я. Куровская. - К., 2005. -210 с.

5. Зіньковська Н. Г. Цинк як антиоксидант і прооксидант за дії на організм коропа / Н. Г. Зіньковська, Ф. Є. Мудра, О. Б. Столяр / Укр. біохім. журн. - 2002. - Т. 74, № 4б, дод. 2. - С. 88.

6. Мехед О. Б. Накопление гербицидов группы 2,4-Д в организме карпа разного возраста // Гидробиол. журн. - 2006. - Т. 42, № 3. - С. 61-66.

7. Ойвин И. А. Статистическая обработка результатов экспериментальных исследований // Патол. физиол. и экспер. терапия. - 1960. - № 4. - С. 76-85.

8. Парфенова И. А. Морфометрические характеристики циркулирующих эритроцитов Scorpaena porcus L. в условиях экспериментальной гипоксии // Наукові записки Тернопільського нац. пед. університету. Серія: біологія. - 2005. - № 4 (27). - С. 82-83.

9. Посібник з клінічної лабораторної діагностики / Під ред. В. Г. Денисюка. - К.: Здоров'я, 1992. $-296 \mathrm{c}$.

10. Скорюков В. И. Практикум по ихтиологии. - М.: Агропромиздательство, 1986. - 268 с.

11. Физиология адаптационных процессов. - М.: Наука, 1986. -635 с.

12. Яржомбек А. А. Справочник по физиологии рыб / А. А. Яржомбек, В. К. Лиманский. М.: Агропромиздательство, 1986. - 192 с.

Надійшла до редколегії 20.12.2006

44

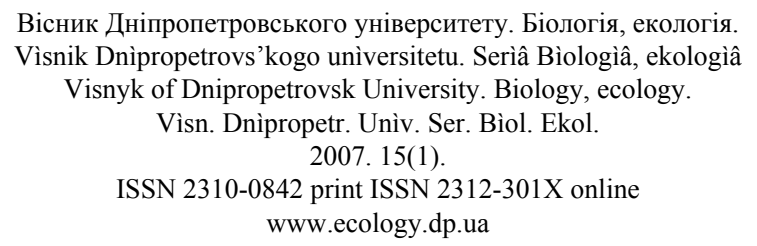

